This item was submitted to Loughborough's Research Repository by the author.

Items in Figshare are protected by copyright, with all rights reserved, unless otherwise indicated.

\title{
A framework to integrate design knowledge reuse and requirements management in engineering design
}

PLEASE CITE THE PUBLISHED VERSION

http://dx.doi.org/10.1016/j.rcim.2007.07.010

PUBLISHER

(C) Elsevier

VERSION

AM (Accepted Manuscript)

LICENCE

CC BY-NC-ND 4.0

REPOSITORY RECORD

Baxter, David, James Gao, Keith Case, Jennifer A. Harding, R.I.M. Young, Sean D. Cochrane, and Shilpa S. Dani. 2019. "A Framework to Integrate Design Knowledge Reuse and Requirements Management in Engineering Design". figshare. https://hdl.handle.net/2134/9798. 
This item was submitted to Loughborough's Institutional Repository (https://dspace.lboro.ac.uk/) by the author and is made available under the following Creative Commons Licence conditions.

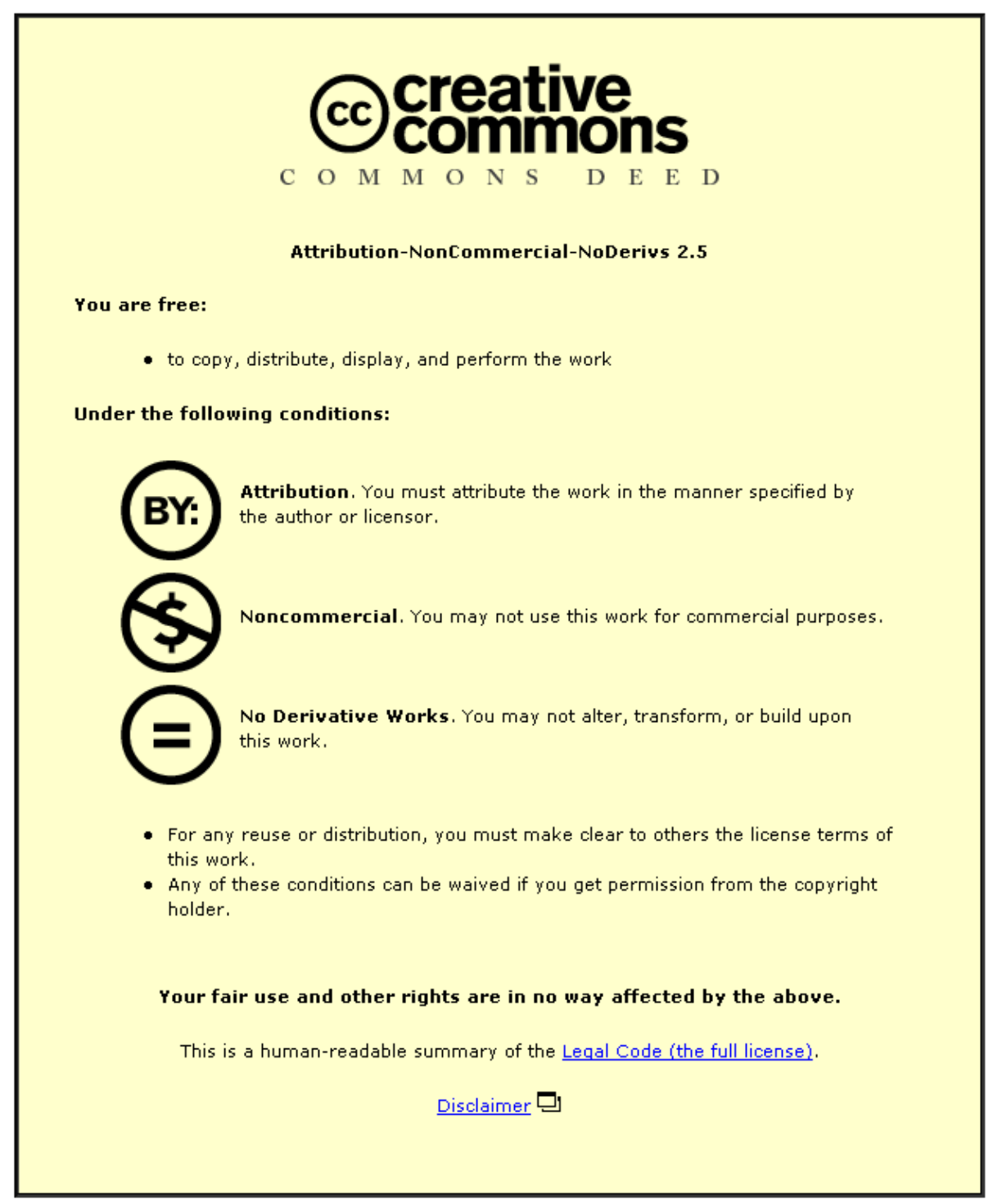

For the full text of this licence, please go to: http://creativecommons.org/licenses/by-nc-nd/2.5/ 


\title{
A framework to integrate design knowledge reuse and requirements management in engineering design
}

\author{
David Baxter ${ }^{1}$, James Gao ${ }^{2}$; \\ Shilpa Dani ${ }^{3}$ \\ 1: Decision Engineering Centre, Cranfield University, Bedfordshire, MK43 0AL, UK \\ 2: School of Engineering, The University of Greenwich, Kent, ME4 4TB, UK \\ 3: Wolfson School of Mechanical and Manufacturing Engineering, Loughborough University, \\ Loughborough, Leicestershire, LE11 3TU, UK \\ Corresponding author. Email: j.gao@gre.ac.uk
}

\begin{abstract}
This paper presents a framework to integrate requirements management and design knowledge reuse. The research approach begins with a literature review in design reuse and requirements management to identify appropriate methods within each domain. A framework is proposed based on the identified requirements. The framework is then demonstrated using a case study example: vacuum pump design. Requirements are presented as a component of the integrated design knowledge framework. The proposed framework enables the application of requirements management as a dynamic process, including capture, analysis and recording of requirements. It takes account of the evolving requirements and the dynamic nature of the interaction between requirements and product structure through the various stages of product development.
\end{abstract}

\section{Keywords}

Engineering design; Design methodology; Design reuse; Design support; Requirements management

\section{Introduction}

Engineering design in today's global and competitive business environment is under increasing pressure to perform better in terms of low time, high quality and high value output that can provide competitive advantage for the organisation. One approach to improve engineering design is through reusing previous knowledge. Organisations in mature markets are in a special position to benefit from knowledge reuse for three key reasons: (1) they know the product well, so are able to produce high quality reusable knowledge (2) the next generation product is likely to have a significant overlap with the previous version (3) knowledge reuse allows more time for innovation, which is especially important since competitive advantage is difficult to achieve in mature domains.

Development time, product quality and customer value are all factors which effective requirements management can improve. By ensuring that the right requirements are met, customer satisfaction can be increased and development times can be reduced through less iteration. Product quality and perceived value is likely to be higher if the customer requirements are better understood and systematically addressed. In engineering design, the project team require a detailed description of the product requirement so that focused design 
work can take place. Various methods for gathering, analysing, selecting, documenting, verifying and managing requirements have been proposed. Most have been in the software development domain, however increasingly requirements management methods are being incorporated into engineering design as the need for requirements management is recognised.

The research approach begins with a literature review in design knowledge reuse and requirements management, to identify appropriate methods within each domain. A framework is proposed based on the identified requirements. The framework is then demonstrated using a case study example: vacuum pump design. A detailed case study with the participating company took place in the design knowledge area, and for this research an additional case study took place in requirements management. The proposals for design knowledge reuse are the result of a previous research project, which is reported in the following section on design knowledge reuse. The proposed framework seeks to integrate design knowledge reuse with requirements management.

This paper will first describe existing approaches for design reuse. Then, proposed methods for managing requirements will be described. Requirements modelling for engineering design will then be described. Then, findings from a case study are used to describe the participating company's approach to requirements management. A proposed framework to support requirements management and design knowledge reuse will then be introduced. The framework is described using the case study data. The final sections will discuss the proposed framework, then introduce suggestions for future work.

\section{Current research on design knowledge reuse}

Design knowledge reuse has been approached from a variety of perspectives. Those discussed here include CAD, design methodology, function and ontology based approaches.

The CAD / CAE research community has contributed a great deal to design knowledge reuse in retrieving CAD models through intelligent systems and case-based reasoning (CBR) (Wang et al., 2002). A further development to intelligent search methods, as in CBR, is intelligent retrieval of information through designer monitoring (Leake and Wilson 2001). Knowledge based design also represents design knowledge reuse, and includes a range of approaches such as knowledge based configuration (Roller and Kreuz 2003). Agent-based methods are also applied to problems such as optimising design concepts (Campbell et al., 1999) and informing design team members of project progress (Harding et al., 2003). CAD based approaches do not support design reuse at the conceptual level: their applicability is limited to detailed design, by which time $80 \%$ of product costs are fixed.

Design ruse approaches to that are based on a design methodology (Shahin et al., 1999) (Blessing 1995) structure the elements of the system around the conceptual framework specified by the design methodology (typically systematic design). Methodology based approaches are best suited to fundamental design problems, where existing solutions are not available: variant design could apply a more structured and specific method to reuse previous solutions.

Design reuse approaches that apply function base the knowledge structure on a functional decomposition, which is a similar approach to quality function deployment (QFD) (Chan and Wu 2002). In the CADET system (Rodgers et al., 2001), (Rodgers et al., 1999), a flexible rule base is applied to describe the domain knowledge - relating product attributes such as 
wheel size to requirement attributes such as 'easy to push'. Another example of a functional perspective on design reuse is the Product Range Model (Costa and Young, R I M 2001) which is intended to support variant design activities through the representation of product functions, relevant design solutions and 'knowledge links' between these attributes. Function enables reuse to take place at a more fundamental level than CAD reuse, and the addition of knowledge links means that product components or assemblies can be retrieved based on the required function. One issue with function based methods is a lack of standard method to represent function. Efforts have been made to standardise the representation approach (Hirtz et al., 2002), however there is still not a commonly accepted method. A further, perhaps more fundamental limitation of the application of function-form mapping for design reuse is that the hierarchical nature of the modelling approaches may mislead the application of a function relationship to a subassembly which by itself does not perform the function. At the base level, none of the individual parts can realise the function. The relationship itself must be described alongside the nature of the relationship in order that it may be successfully reapplied.

Ontologies in design are developed for a variety of applications, each one enabling reuse of knowledge through creating a representation of the domain. Ontologies enable understanding of concepts, data elements, and relationships between concepts. An automotive seat specification ontology was developed which enables a shared understanding of the product and relationships between product concepts (Kerr et al., 2004). Another example of an ontology-based approach is the function-way server, which applies a function ontology along with a product ontology to support conceptual design (Kitamura and Mizoguchi 2003). Ontology can be applied to the whole range of product attributes, including form, function, and behaviour.

Design reuse remains a developing area, and many approaches have been developed. Further effort is required to understand the needs of knowledge users and producers in order that appropriate methods can be applied (Markus 2001) (Busby 1999) (Finger 1998).

\subsection{Process-based design reuse}

An additional design reuse perspective is that of process: the design process as a central element of a design reuse system (Baxter and Gao 2004) (Baxter and Gao 2005), (Baxter et al., 2006). It has been suggested that the design process is a driver of design reuse for decision making at all stages of product development (Inns and Neville 1998). Process based approaches have been characterised as one of three types: engineering (systematic design methodologies), business process, and CAD / CAE based (Lu et al., 2000). Notable process based methods include Signposting and the Design Roadmap. Signposting (Clarkson and Hamilton 2000) is a parameter driven task-based model of the design process. The method uses a measure of confidence levels in key design parameters as the basis for identifying, or signposting, the next design task. The Design Roadmap (DR) method provides a formal method to represent the design process (Park and Cutosky 1999). The method enables the representation of feedback and feedforward processes, which are common in design yet uncommon in design process representations. The DR process data model enables a variety of graphical representations, or views. Graph, matrix, tree and list views are supported.

The principle of the process based knowledge reuse system is knowledge reuse through interaction between process knowledge, task knowledge and product knowledge. Assuming that the organisation has developed similar products in the past, a large amount of product knowledge is required for, and embedded in, a design process model. This model is stored in 
the process knowledge database. Computational methods are applied to product data, and 'how-to' knowledge is provided in support of tasks. This task automation and support knowledge is stored in the task knowledge database. During the design process, an ontology based product model is applied. This product model is stored in the product knowledge database. The resulting system architecture is shown in figure 1. The diagram shows that product, task and process knowledge are stored in databases and retrieved by the design reuse application.

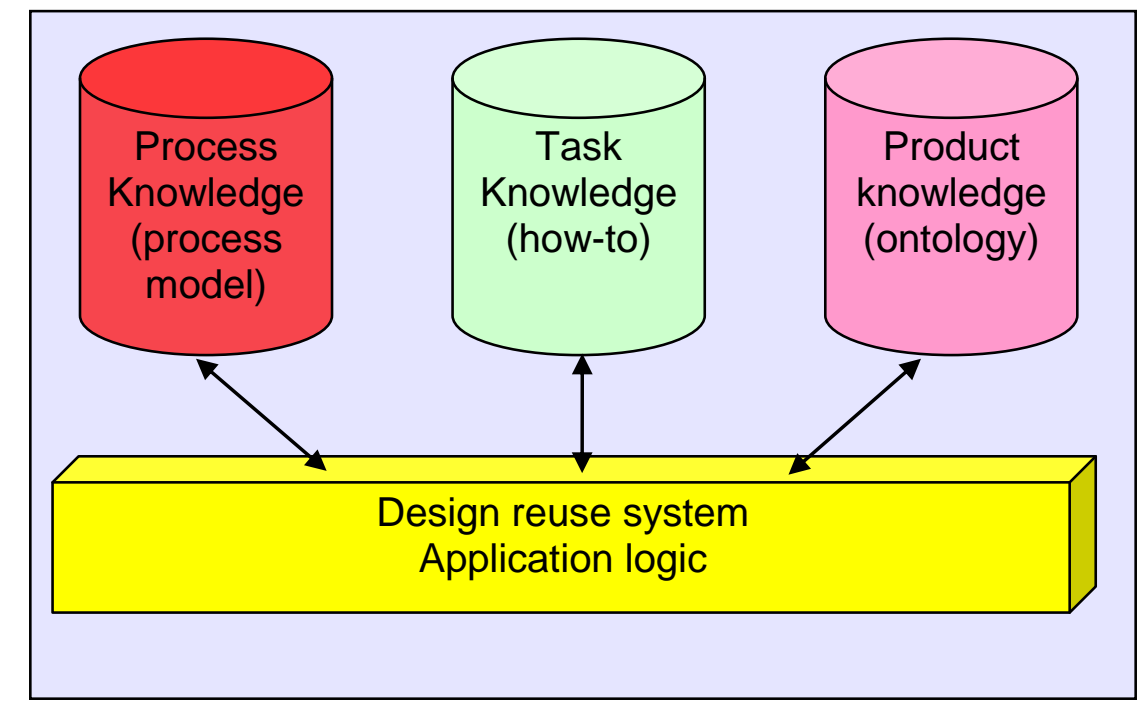

Figure 1: System architecture

In a variant design scenario, a formal representation of process can be applied. The combination of process and ontology based reuse will support a wide range of reuse situations in early design: application of a best practice design process, function based component and assembly selection (through design ontology), recording design decisions and evolving product model (through design ontology) and methodology guidance for fundamental design problems and design analysis (through process representation).

\section{Current research on requirements practices}

Requirements are the subject of an extensive body of literature in the information systems domain. Some of the work from this domain has been investigated with a view to making recommendations for engineering design. Requirements practices include gathering, analysing, selecting, documenting, verifying and managing (Davis and Zowghi 2006). These practices are often discussed together under the umbrella 'requirements management'. Requirement management (RM) methods provide a means to document requirements and check their progress through the project. There are a large number of proposed approaches for managing requirements, and several commercial software tools are available. It is important to treat requirements management as a process and not an event, since requirements change and their status must be tracked throughout the project. (Halbleib 2004).

"Requirements management is a critical part of the development process, not only for software, but for all products." (Turk 2005) p4 
Of three levels of RM adoption, most firms are at level 1: an ad-hoc RM process, hard to estimate and control costs, poor customer satisfaction, lack of RM planning and review procedures (P. et al., 1999). Requirements management support is needed in engineering design. The requirements management process records and tracks the requirements through the development process. Requirements elicitation method selection must be considered for each specific case (Hickey and Davis 2004). Requirements analysis follows, breaking down the requirement. The selection of analysis method also depends upon the needs of the resulting application (A. et al., 2006). Selection and documentation of requirements are collaborative tasks whose structure depends on the management method.

\subsection{Engineering design requirements modelling methods}

Design requirements, in product modelling terms, are synonymous with product specifications. This section describes a selection of existing work that has taken place in the domain of product modelling with an emphasis on requirements. For a more complete review of research into design requirements, see (Culley 2002). Product modelling has been applied to many aspects of design outside of geometric modelling, including major efforts to include a complete design representation of form, function and behaviour (Szykman et al., 2000). In information systems, problem / solution mappings can be expressed as logical relations (Culley 2002). In engineering design however, mapping between the product and solution remains at the abstract level. There are problems with the tight coupling of product requirements with product structure. This must be considered when assessing whether RE methods are applicable to engineering design.

McKay claims that software and electronic products differ from mechanical products in that the geometry of mechanical parts influences their functionality, and that a current barrier to innovation is a lack of distinction between product features that enable manufacture and product features required by the customer. Their proposed method provides a means to represent a product requirement that can be linked to the physical product structure (McKay et al., 2001). Without a statement of requirements, optimal redesign is not possible (e.g. redesign based on a previous product shape). The representation scheme for product specifications addresses each of the requirements management stages described by Halbleib (Halbleib 2004) excepting traceability. However, because the product elements are tightly coupled, requirements that are part-met by multiple functional structures will cause problems. Changed requirements or changed physical elements will result in mapping problems. Therefore, due to these apparent dynamic limitations this method supports requirements specification but not requirements management.

Methods for modelling product specifications include extensions of the function / means tree in which functional requirements, design parameters and constraints are modelled together with additional information about the requirement (P. and H.L. 2000). This method assumes a direct relationship between product function and structure. Again, this tight coupling of solution and structure could cause problems. The solution was tested in an automotive setting, where traditionally, the OEM creates the specification. With the specification in the hands of the OEM, yet a shifting of design expertise from OEM to supplier, this could result in a suboptimal configuration. If the supplier is to recreate the specification to suit their environment, then this doubles the required work. An alternative method is proposed (Kerr et al., 2004) in which the product (seat) specification is produced using an ontology that represents shared understanding of the product. The OEM can make a specification which is directly relevant to the supplier, and which states several important design parameters up 
front. Not only does this method provide unambiguous specification, it also provides the initial parameter set that can be applied to the configuration of the product. The ontological framework can also be applied to requirements management (Roy et al., 2004) by adding information and process layers. The process layer was not addressed, and is a key part of the method proposed in this paper.

An alternative function-based hierarchical method (Nilsson and Fagerstrom 2006) proposes a mapping between product structure and function. The representation includes purpose, function realisation and function materialisation. Function can be allocated onto parts on a 'many to any' basis, enabling separate function realisation from the manufacturing. In other words, any number of part structures can be associated with realising a given function. The system therefore recognises two crucial elements of product modelling: that stakeholders and their requirements must be identified, otherwise important requirements are missed; and that function is not directly linked to the physical product structure. This work was in part based on the requirements intelligent information framework (Harding et al., 2001), which used fuzzy logic to determine product attributes from qualitative requirements. Each of the product function based modelling approaches described here make reference to the functional requirements and design parameters developed by Suh (Suh 1990).

Requirements modelling in engineering design must recognise the problems associated with a tight coupling of product requirements and product structure. Whilst a mapping between requirements and product structures can support design reuse in a similar way to functionform mapping, it inherits the need for a shared view. The application of ontology can support the need for a shared view. The mapping problem exists since form / function and requirements / product structure do not have direct relationships other than a logical, or high level abstract view.

\subsection{Requirements definition and design methodology}

Several design methodologies exist, and many of them include elements that relate to the translation of customer needs into engineering specifications. Systematic design is a structured approach to product design (Pahl and Beitz 1988). This rigorous method ensures that a product specification describing product sub-systems, assemblies and details of their requirements plays a central role in the development process. Quality Function Deployment (QFD) requires that customer needs are identified, quantified, translated into technical requirements and subsequently measured (against how well the customer need is satisfied). The aim of QFD is to improve the quality of design, and as such many publications are devoted to the application of QFD to product development (see (Chan and Wu 2002) for an extensive selection). Poor product definition is a factor in $80 \%$ of all time-to-market delays (Ullman 2003), and 35\% of all product development delays are due to specification creep. Ullman suggests that QFD can help through creating measurable design targets and highlighting gaps in knowledge of the problem.

Axiomatic design is a method devoted to the application of fundamental principles that make designs good. The representation of design requirements is addressed as part of a method to redefine them such that the functional requirements remain independent (Suh 1990). It is recognised that product requirements can override the desire to make functional requirements independent, as is the case with side opening refrigerators. 
Most design requirements are identified during the design process, and not from the customer (Blessing, Chakrabarti, A. and Wallace 1995), therefore a large proportion of the requirement management effort takes place during solution generation and embodiment design. Reinertsen suggests that requirements should be managed using a progressive approach, in which only a limited number of performance characteristics are fixed early on (Reinertsen 1997). He proposes that the development team create a product advert or 'catalogue-page' specification, reasoning that if it's not important enough to be in the catalogue, it's not important enough for the product specification. A more detailed specification simply creates more constraints for the designers without creating more value for the customer.

Requirements are emergent; a result of form. With a variant or evolutionary design (the next member or generation of a product family), many of these emergent requirements remain the same as the previous generation of products. By identifying relationships between these requirements and the solution principles, the knowledge can be reused. Additional knowledge of manufacturing, operation, testing and servicing could also be related to the solutions. The literature has shown that the requirement source is a critical element that must be recorded if this knowledge is to be successfully applied: internally generated requirements need only be considered where the context (product structure) is the same.

\subsection{Literature summary}

Process-based design reuse will be applied in combination with an ontology based product model. This will support the application of process (design methodology and best practices) alongside product and task knowledge reuse. Requirements management practices should be recognised, in terms of capturing, analysing and managing the requirement through the NPI process. A minimal requirements set should be sought at the beginning of the project, in order to minimise constraints and focus on the value proposition of the product.

\section{Requirements management case study}

The aim of the research is to develop a framework that supports requirements management as well as design knowledge reuse. The literature review has identified various features that the requirements management method should apply. It has also identified a design knowledge reuse framework. The integrated framework will be presented, and then assessed through a case study.

This research is taking place in the context of variant design, in which a mature and well known yet at the same time specialist and relatively complex product is required as a subsystem for a larger customer system: vacuum pumps for semiconductor processes. The market is facing ever increasing quality demands, price competition and regulation. The designers are required to achieve their performance goals with varying levels of engineering specification. Vacuum pumps for semiconductor processes must meet very demanding requirements for service life within a harsh operating environment. The exact constituents of the process gases used in the semiconductor manufacturing process have a major impact on service life, yet they are competitively sensitive. As a result, the designers may have to work with an incomplete specification. The products are viewed by the tier 1 producer as commodity items, available from a (small) number of (specialist) suppliers. As such, the motivation for the customer to spend time making a detailed engineering specification for these products is relatively low. The capability to determine customer needs without the assistance of the customer offers substantial potential for competitive advantage in such markets. As such, substantial benefit could be gained from a method that enables 
requirements management as well as supporting the design process and design reuse. The learning gained from translating customer needs to working solutions could be applied to new projects through such a framework. Internally generated requirements, either through technology led solutions or projections of customer needs, must also be addressed.

\subsection{Requirements management process capture}

This section will describe a case study that investigated the approach to managing requirements for vacuum pump design. Several managers in the company were interviewed. These included project managers, sales managers, product managers and technical specialists. In total, 12 managers were interviewed. The interview process was semi-structured, with the aim of developing an agreed model of the requirements management process. The modelling method applied was IDEFØ (NIST 1993). After each interview, the current understanding of the requirements management process was mapped and sent to the participant for review. Several follow-up interviews took place to validate the model. After several iterations, the process model was agreed upon. The top level of the process is shown in Figure 2:

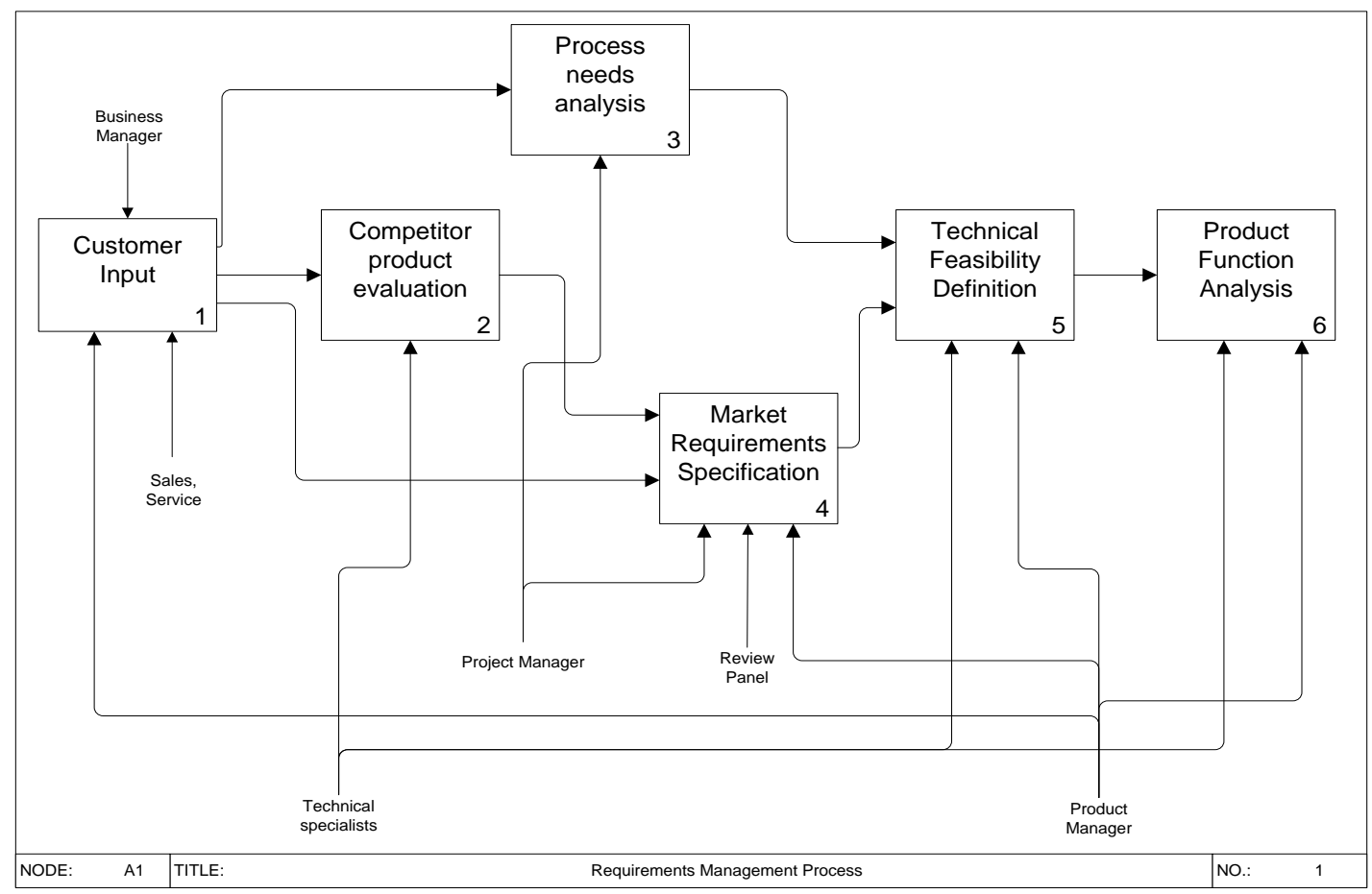

Figure 2: Requirements Management Process

The requirements management method shown in Figure 2 has a typically fuzzy front end. Customer input is provided to the product development team via sales, service and field based product specialists. A competitor product evaluation is carried out by the technical specialists. This is a fairly typical approach to competitor product analysis: buy a competitor product and carry out a detailed analysis. The process needs analysis relates to the product requirement. The product forms part of a manufacturing process, so the specification of that process includes required vacuum performance and the chemicals involved in the process. The market requirements specification is a significant document, and is the main source of the product target requirement. It contains details of customer requirements alongside competitive targets based on competitor pricing and performance. The process needs analysis is the major source 
of constraints on the target requirements, so together these two requirements sources lead to the development of the engineering specification, which is referred to as the technical feasibility definition. The reference to feasibility ensures that the specified product is within the current capability. What this process does not show is the R\&D input to product development: internal development is a means to achieve competitive advantage rather than a customer requirement.

The process is managed without a formal requirements management methodology. It has been found that the quality of requirements management methods has a strong impact on the quality of the emergent design (Chakrabarti et al., 2004). The predominant view expressed in the literature is that a requirements management methodology is an essential element of the product development process, and that without it a project is more likely to fail. However, whilst there is correlation of good requirements management with product success, not all good practices result in a good product, and some good products are created without a clear RM method (Davis and Zowghi 2006). The capability to produce a good result without a good RM method is likely to represent a good understanding of the user needs by the development team. The case study company are market leaders. Because they do not apply a formal RM method does not mean that their products will not meet the customer requirements. However, growing pressure to reduce development time, increase product quality and produce increasingly complex products is resulting in an increased interest in requirements management methods. At a basic level, a requirements management system may simply be an aid for recording and recall of product requirements: even in a small sized project, experienced designers leave a number of requirements unsatisfied (Chakrabarti et al., 2004). In a large project, a structured RM method would help to support the satisfaction of requirements.

\section{Integrated product model: proposed framework}

The aim of this proposed framework is to manage product requirements as part of an integrated product knowledge reuse method. The requirements management element should support gathering, analysing, selecting, documenting, verifying and managing. It should also reflect the minimum specification approach, and must be dynamic, to deal with changing requirements. Design knowledge reuse will be achieved through the process based method described in section 2. A design process model, task knowledge and product knowledge (product ontology) are combined to enable reuse of design knowledge.

Figure 3 shows a diagram of the framework components. The arrows indicate general process flow: relationships can be created between all of the constituent elements. The remainder of this section discusses the constituent elements of the framework. 


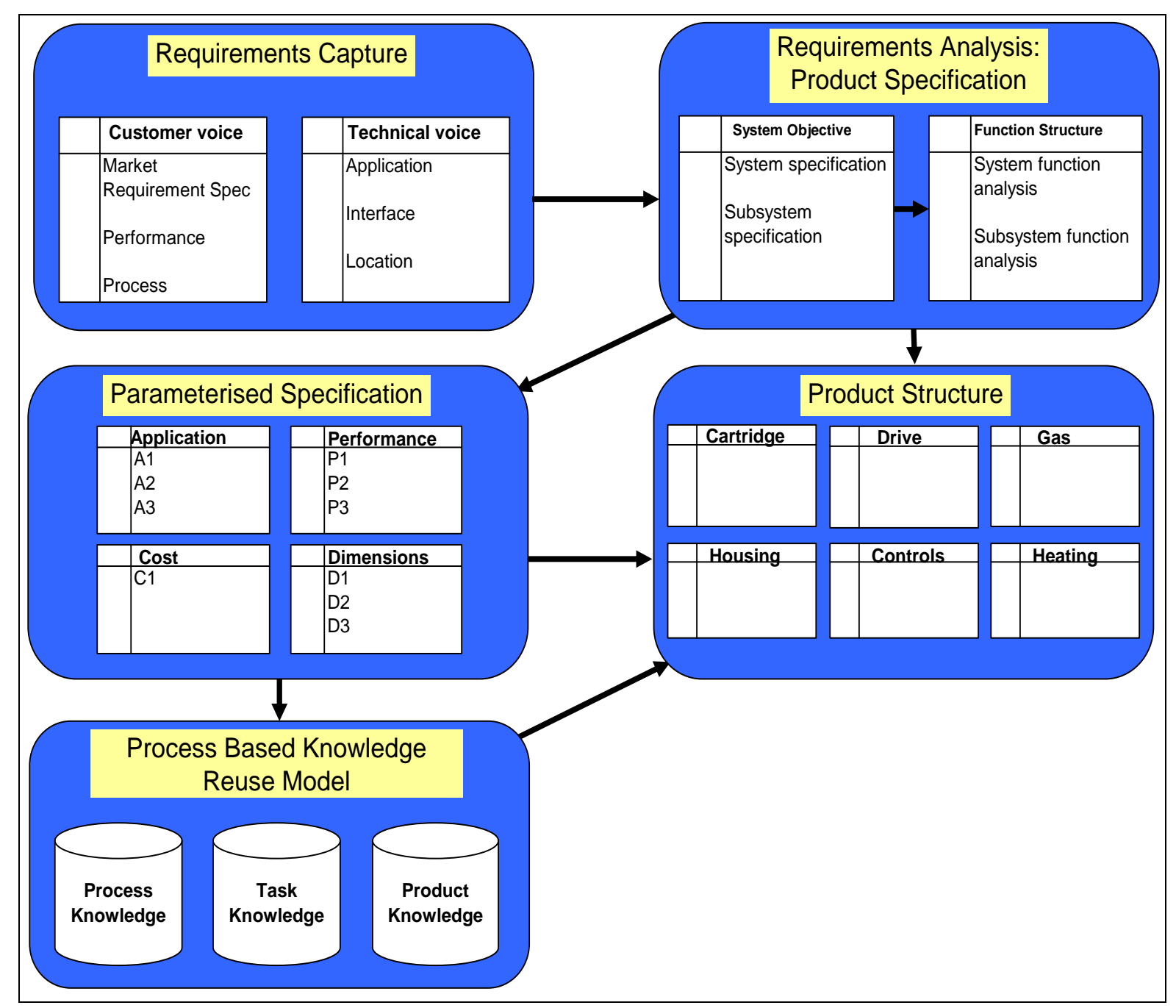

Figure 3: Integrated Product Model

The process for applying the framework begins with requirements capture. In the second stage, the requirements are analysed and selected and used to create a technical specification and product function structure. This specification is applied to a parameterised product specification and a product structure. The process based knowledge reuse method is applied to the process and data transactions throughout the application of the framework. The framework components will now be described in turn, in more detail.

\subsection{Requirements capture}

The requirements capture process applied by the case study company has been described in Figure 2. This is intended to enhance that process through the addition of a clearly defined structure. It also applies the 'minimal requirements' approach, as identified in the literature. The initial requirements set is gathered. The customer perspective is supported by a technical perspective, to support internal development and to overcome the requirements specification problems described in section 4. Customer facing personnel including sales, staff and product managers come together to share their views and generate the 'customer voice' specification. The requirement will include details of required product performance and the operating environment of the target process. The technical viewpoint includes specific application challenges, required software or hardware interfaces and location class (i.e. 00 clean room). The result of the requirements capture process is recorded in a database. 


\subsection{Requirements analysis: product specification}

Analysis of the requirements is carried out, and an objective specification for the product is created along with a system function analysis. Each of these is broken down in a hierarchical fashion to describe subsystem specifications and subsystem functional analysis. This specification and functional structure represents the product requirement to be managed dynamically through the design process. The mapping between requirements capture and analysis is indirect and conceptual; there is not a direct relationship between the customer requirement and product specification. There is a conceptual link. Making this link visible and maintaining the original data helps support the progression from customer requirement to engineering specification. It is also necessary to maintain a requirements history throughout the project, since the requirements change.

\subsection{Parameterised Specification}

In order to provide a link between product structure elements and product function, a parameter set is defined. In the case study example, the parameterised specification data set has 4 categories: Application, Cost, Dimensions and Performance. Each category can have several attributes: $A_{1}, A_{2} \ldots A_{n}, C_{1}, C_{2} \ldots C_{n}, D_{1}, D_{2} \ldots D_{n}, P_{1}, P_{2} \ldots P_{n}$. The data set should remain as small as possible, to minimise unnecessary constraints for the design team. In general, it should describe the main value proposition of the product in the 'catalogue description' sense (Reinertsen 1997). Some of the data are represented not as single numbers, but as a complex set such as the vacuum requirement performance curve.

\subsection{Process based knowledge reuse model}

The parameterised specification is linked to the process based knowledge reuse model. The specification data is stored in the product knowledge database. The product knowledge database is structured by a design ontology, which defines the terminology, product hierarchy and data types. The stored data is used as an input to design process tasks. A detailed task model guides the designers through the various product design tasks. As the tasks are completed, design data is stored in the system: as product parameters are generated or updated by specific design tasks. The integrated product model stores the result of the requirements process as parameters of the product knowledge model. A more complete description of the process based knowledge reuse model can be found in (Baxter et al., 2006). The key addition in this framework is the method to capture, analyse and manage product requirements.

\subsection{Product structure model}

The simple parameterised specification represents a combined market and technical perspective of what the product requirements are in terms of application, performance, size and cost targets. The product structure model comprises of a data set describing the solution concept to meet the needs of that requirements set. The product structure model is arranged in a modular fashion to enable the reuse of complete product modules where appropriate. The future intention is to build a series of parametric CAD models that use the completed product structure objects as inputs. The current situation is that the designers manually apply the parameters to the development of the 3D model.

\section{Discussion}

The development of this integrated product model is taking place as part of a research project which aims to provide a method to reuse engineering design knowledge (Baxter and Gao 2004) (Baxter and Gao 2005), (Baxter et al., 2006). The approach is based on the premise 
that the design process itself represents a large amount of design knowledge, and that by creating a formal representation of the design process there is an opportunity to provide structure to enable the retrieval of information that is task relevant. Developing the design process model highlighted the fact that many of the product parameters are a decomposition of the product requirements. Product model parameters are used as inputs to the design tasks. These include early performance analysis tasks like product performance modelling and dynamic analysis, through to the initial product layout tasks. Because the product parameters can be related (through the process model and product model) to the product requirements, the method of capturing the requirements was shown to be a critical input to the process.

Process, task and product knowledge are the three key elements of the design reuse system (Baxter et al., 2006). Originally, the approach to managing requirements was through an interaction between the process model and product parameters - that is, the requirements parameters were a part of the product knowledge. The extended mapping proposed in this paper recognises the high importance of requirements not only in terms of recording the parameters, but also in terms of the method of capturing the requirement and the dynamic interaction between the requirement and the product structure through the development cycle. This is achieved through the mapping between both the functional and physical product models, which becomes more tightly defined as product development progresses. A further contribution of the method is project support. The process model provides a method based on company best practices, which describes the sequence, data, information inputs and outputs for each task in the product development project.

The capability to link requirements to product structures through function analysis has been shown in previous work (Nilsson and Fagerstrom 2006) (McKay et al., 2001). This work extends the modelling domain to include a design knowledge framework that includes design parameters, a design process model, and knowledge based methods. The relationships between the domains are often multiple and complex. Sources of requirements, design parameters, and design changes can be lost. The application of the design process model provides an additional framework within which the design work can be carried out using a best practice method. The process model has relationships with design parameter model, which ensures that required parameters are assigned at the correct time.

\section{Conclusion \& further research}

The framework proposed in the paper adds requirements management capability to a design knowledge reuse method. Mapping between the various product domains (requirements capture, requirements analysis, specification, and product structure) links the product structure to the requirement source. The database structure provided by the design knowledge reuse system supports dynamic management of the emergent requirements and developing design data. The proposal was based on the findings from a literature review that identified the components of a requirements management method: gathering, analysing, selecting, documenting, verifying and managing.

\subsection{Further research}

The requirements management method described through the case study could be improved through systematic analysis and a comparison with best practices in the literature. This best practices process could then be transferred to the design knowledge reuse system. The first stage of this is process modelling. Product and requirements data should then be added to the 
process model. Finally, task descriptions (how-to) and links to additional resources should be added. This best practices approach to requirements management must be carefully verified.

A second area for further work is creating a formal link between the product structure and 3D CAD through parametric modelling. By selecting high value parts, the development of parametric models could further enhance the design process. This approach requires careful analysis in order to determine the appropriate parts: not all components will warrant the high effort required to develop parametric models. It could benefit from design knowledge support: a process model with supporting product data and how-to task descriptions for the parametric modelling process. There is not currently a clear path for storing such data.

\section{Acknowledgements}

The authors would like to acknowledge the continued professional support of BOC Edwards, and the EPSRC in funding this project through the Cranfield University IMRC and Loughborough University IMRC.

\section{References}

Baxter, D.I., Gao, J.X., Case, K., Harding, J., Young, R., Cochrane, S. and Dani, S. (2006) An Engineering Design Knowledge Reuse Methodology Using Process Modelling. Research in Engineering Design. accepted for publication 2006

Baxter, D.I. and Gao, J.X. (2004) Process based representation for design knowledge, In: Proceedings of the 2nd International Conference on Manufacturing research 2004 (ICMR 2004). Sheffield Hallam University, Sheffield, UK.

Baxter, D.I. and Gao, J.X. (2005) Process based design knowledge reuse through process and product representation, In: Proceedings of the 12th CIRP Life Cycle Engineering Seminar (CIRP LCE) 2005. Grenoble, France.

Blessing, L.T.M. (1995) A process-based approach to design. Colloquium Digest-IEE. 49.

Blessing, L., Chakrabarti, A. and Wallace, K. (1995) A design research methodology, In: Proceedings of the International Conference on Engineering Design (ICED '95).

Busby, J.S. (1999) The Problem with Design Reuse: An Investigation into Outcomes and Antecedents. Journal of Engineering Design. 10, 3. 277-97

Campbell, M.I., Cagan, J. and Kotovsky, K. (1999) A-Design: An Agent-Based Approach to Conceptual Design in a Dynamic Environment. Research in Engineering Design. 11, 3. $172-92$

Chakrabarti, A., Morgenstern, S. and Knaab, H. (2004) Identification and application of requirements and their impact on the design process: a protocol study. Research in Engineering Design. 15, 1. 22-39

Chan, L.-K. and Wu, M.-L. (2002) Quality function deployment: A literature review. European Journal of Operational Research. 143, 3. 463-97

Clarkson, P.J. and Hamilton, J.R. (2000) Signposting, A Parameter-driven Task-based Model of the Design Process. Research in Engineering Design. 12, 1. 18-38

Costa, C.A. and Young, R I M (2001) Product range models supporting design knowledge reuse. Proceedings of the Institution of Mechanical Engineers - Part B - Engineering Manufacture. 215, 3. 323-38

Culley, S.J. (2002) Current research in the engineering design requirement. Proceedings of the Institution of Mechanical Engineers - Part B - Engineering Manufacture. 216, 3. 375-89

Davis, A. and Zowghi, D. (2006) Good requirements practices are neither necessary nor sufficient. Requirements Engineering. 11, 1-3 
Finger, S. (1998) Design reuse and design research - keynote paper, In: Engineering Design Conference '98. Brunel University, UK. Professional Engineering Publishing Ltd

Halbleib, H. (2004) Requirements Management. Information Systems Management. 21, 8-14

Harding, J.A., Popplewell, K. and Cook, D. (2003) Manufacturing system engineering moderator: an aid for multidiscipline project teams. International Journal of Production Research. 41, 9. 1973-86

Harding, J.A., Popplewell, K., Fung, R.Y.K. and Omar, A.R. (2001) An intelligent information framework relating customer requirements and product characteristics. Computers in Industry. 44, 1. 51-65

Hickey, A. and Davis, A. (2004) A unified model of requirements elicitation. Journal of Management Information Systems. 20, 65-84

Hirtz, J., Stone, R.B., McAdams, D.A., Szykman, S. and Wood, K.L. (2002) A functional basis for engineering design: Reconciling and evolving previous efforts. Research in Engineering Design. 13, 2. 65-82

Inns, T. and Neville, P. (1998) Establishing a company-level design process to facilitate design reuse, In: Proceedings of the Engineering Design Conference 1998. Brunel University, UK.

Kerr, C., Roy, R. and Sackett, P. (2004) A product ontology for automotive seat specification, In: The 2004 ASME International Design Engineering Technical Conferences \& The Computer and Information in Engineering Conference (ASME DETC/CIE 2004) - 30th Design Automation Conference (DAC). Salt Lake City, Utah, USA.

Kitamura and Mizoguchi (2003) Ontology-based description of functional design knowledge and its use in a functional way server. Expert Systems with Applications. 24, 2. 153-66

Leake, D.B. and Wilson, D.C. (2001) A case-based framework for interactive capture and reuse of design knowledge. Applied Intelligence. 14, 77-94

Lu, S., Cai, J., Burkett, W. and Udwadia, F. (2000) A Methodology for Collaborative Design Process and Conflict Analysis. ANNALS- CIRP. 49, 1. 69-74

Markus, M.L. (2001) Toward a theory of knowledge reuse: types of knowledge reuse situations and factors in reuse success. Journal of Management Information Systems. 18, 1. 57-93

McKay, A., Pennington, A.D. and Baxter, J. (2001) Requirements management: a representation scheme for product specifications. Computer-Aided Design. 33, 511-20

Nilsson, P. and Fagerstrom, B. (2006) Managing stakeholder requirements in a product modelling system. Computers in Industry. 57, 167-77

NIST (1993) Integration Definition For Function Modeling (IDEF0).

Pahl, G. and Beitz, W. (1988) Engineering Design: a systematic approach. The Design Council, London.

Park, H. and Cutosky, M.R. (1999) Framework for modeling dependencies in collaborative engineering processes. Research in engineering design. 11, 2. 84-102

Reinertsen, D. (1997) Managing the Design Factory. The Free Press, New York.

Rodgers, P.A., Caldwell, N.H.M., Clarkson, P.J. and Huxor, A.P. (2001) The management of concept design knowledge in modern product development organizations. International Journal of Computer Integrated Manufacturing. 14, 1. 108-15

Rodgers, P.A., Huxor, A.P. and Caldwell, N.H.M. (1999) Design Support Using Distributed Web-Based AI Tools. Research in Engineering Design. 11, 1. 31-44

Roller, D. and Kreuz, I. (2003) Selecting and parameterising components using knowledge based configuration and a heuristic that learns and forgets. Computer-Aided Design. 35, 12. $1085-98$ 
Roy, R., Kerr, C. and Corbett, J. (2004) Design requirements management using an ontological framework. CIRP Annals - Manufacturing Technology. 54, 109-12

P., S., I., S. and S., V. (1999) Capturing the Benefits of Requirements Engineering. IEEE Software. 16, 78-85

P., S. and H.L., J. (2000) Computer modelling of design specifications. Journal of Engineering Design. 11, 317-29

Shahin, T.M.M., Andrews, P.T.J. and Sivaloganathan, S. (1999) A design reuse system. Proceedings of the Institution of Mechanical Engineers, Part B: Journal of Engineering Manufacture. 213, 6. 621-7

Suh, N.P. (1990) The Principles of Design. Oxford University Press, Oxford.

A., S., G., P. and L., Z. (2006) Comparing requirements analysis methods for developing reusable component libraries. Journal of Systems and Software. 79, 273-89

Szykman, S., Sriram, R.D. and Bocheneck, C. (2000) Design repositories: engineering design's new knowledge base. IEEE Intelligent Systems \& Their Applications [H.W. Wilson - AST]. 15, 3. 48-55

Turk, W. (2005) Requirements Management. Defense \& AT-L. 34, 10-3

Ullman, D.G. (2003) The Mechanical Design Process. McGraw-Hill, London.

Wang, L., Weiming-Shen, Xie, H., Neelamkavil, J. and Pardasani, A. (2002) Collaborative conceptual design - state of the art and future trends. Computer-Aided Design. 34, 13. 981-96 